\title{
Article
}

\section{'Such endings that are not over': The slave trade, social dreaming and affect in a museum}

Manley, Julian and Trustram, Myna

Available at http://clok.uclan.ac.uk/13593/

Manley, Julian ORCID: 0000-0003-2548-8033 and Trustram, Myna (2018) 'Such endings that are not over': The slave trade, social dreaming and affect in a museum. Psychoanalysis, Culture and Society, 23 (1). pp. 77-96. ISSN 10880763

It is advisable to refer to the publisher's version if you intend to cite from the work. DOI: $10.1057 / 541282-016-0032-x$

For more information about UCLan's research in this area go to http://www.uclan.ac.uk/researchgroups/ and search for <name of research Group>.

For information about Research generally at UCLan please go to http://www.uclan.ac.uk/research/

All outputs in CLoK are protected by Intellectual Property Rights law, including Copyright law. Copyright, IPR and Moral Rights for the works on this site are retained by the individual authors and/or other copyright owners. Terms and conditions for use of this material are defined in the policies page.

\section{CLoK}

Central Lancashire online Knowledge www.clok.uclan.ac.uk

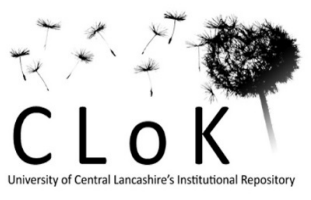


Cover sheet ('An article', 7963 words excluding biographies, abstract and references)

Julian Manley works at the Psychosocial Research Unit (PRU), University of Central Lancashire. He has spent many years researching the potentials and uses of Social Dreaming in psychosocial contexts. He is Chair of the Academic Research Committee of the Gordon Lawrence Foundation that promotes Social Dreaming. His research interests are centred around Social Dreaming, visual thinking and the development of research methods that use affect as a complementary form of cognition.

Psychosocial Research Unit,

School of Social Work, Care and Community, University of Central Lancashire, Preston PR1 2HE, UK.

(+44) (0) 1772893478

jymanley@uclan.ac.uk

Myna Trustram works at Manchester School of Art (Manchester Metropolitan University). For many years she was a history museum curator. Her research and writing spans museology, performance and creative non-fiction, all from a psychodynamic perspective. Her main project is called 'Museum Melancholy: Loss in the midst of plenty'. Recent publications include: 'Little Madnesses of Museums' in Little Madnesses: Winnicott, Transitional Phenomena and Cultural Experience, edited by Annette Kuhn, 2013.

Research Associate Manchester School of Art Manchester Metropolitan University Righton Building, room 1.11

Cavendish Street Manchester M15 6BG UK

01612471118 m.trustram@mmu.ac.uk 


\begin{abstract}
'Such endings that are not over': The slave trade, social dreaming and affect in a museum

The paper explores Social Dreaming as a method for understanding the affective responses to one of the exhibitions that marked the bicentenary of the 1807 Act that abolished the British slave trade: Breaking the Chains: The Fight to End Slavery at the British Empire and Commonwealth Museum (BECM) in Bristol. It asks whether Social Dreaming can serve the evolving purposes and mission of museums and their role in society. The theory and practice of Social Dreaming is described and findings are interpreted from a psychosocial and Deleuzian perspective. Finally the value and potential of Social Dreaming is discussed as a process for attending to audience reactions to disturbing exhibitions.
\end{abstract}

Key words: museum, social dreaming, affect, slavery, psychosocial 
'Such endings that are not over': The slave trade, social dreaming and affect in a museum

\section{Introduction}

Avery Gordon's phrase 'such endings that are not over' refers to the apparent ending of racial slavery in the USA (2008, p. 139). It teases us in its mild denial of history. Can one ever draw the curtain on the horrors of historical slavery and would one ever want to? If we apply such questions to history that has been selected for museum displays, we not only question a method of interpreting history, but the way it might be represented. Central to many such displays is a narrative of facts that can be verified for historical accuracy. This essay examines how facts about the slave trade were displayed in the exhibition Breaking the Chains: The Fight to End Slavery at the British Empire and Commonwealth Museum (BECM) in Bristol and how it is sometimes only with difficulty that the museum visitor can access a factual world through the vulnerable non-factual self. We examine the use of Social Dreaming (Lawrence, 2005; Manley, 2014) as a way of accessing the subjectivities of the self in this museum context, and investigate the potential use of Social Dreaming in museums.

\section{Breaking the Chains: The Fight to End Slavery}

In 2007 hundreds of museums prepared exhibitions to mark the bicentenary of the 1807 Act, which abolished the British slave trade. Slaves were emancipated through a further act in 1833, but even then a system of apprenticeship was introduced which kept the freed slaves tied into unpaid labour for fixed terms. In 1838 this latter system was abolished. This distinction between the slave trade and slavery is easily elided in loose talk about slavery being abolished in 1807. It is central to the argument of this essay that one of the darknesses of slavery is that historical 
narrative is not necessarily a safe haven for an examination of such a tumultuous theme. In addition to this difficulty, in their efforts to commemorate the abolition of the slave trade, the museums were also trying to manage competing demands 'fraught with sensitivities and tensions' (Smith, 2010b, p.24), which may have been beyond the remit of historical narratives: on the one hand they were celebrating abolition and on the other embracing the experiences of African and African-Caribbean communities within wider narratives of 'Britishness'.

Bristol was one of the main British ports involved in the trading of slaves from West Africa to the British Caribbean during the 17th and 18th centuries. The Breaking the Chains exhibition was one of the more substantial exhibitions of the bicentenary commemorations (Dresser, 2009, p.235; Prior 2007). It consisted of galleries covering West Africa; trading with Europe; the capture and enslavement of people; slavery in the British Caribbean and the abolition. Visitors were initially confronted with an image depicting slaves confined in the hold of a ship (Figure 2), and then guided through the various sections, culminating in the celebration of the resistance to slavery in the Caribbean. Inevitably strong reactions and emotions were evoked in visitors. Prior, a historical consultant to the BECM comments that 'transatlantic slavery and African-Caribbean history in general are not yet considered a normal or ordinary part of a British museum's brief. The perceived difficulties of mounting exhibitions or planning ancillary events on these topics lead to a "curating by committee" approach which undermines bold and imaginative treatments and waters down direct language' (Prior, 2007, p.200). Despite this, Dresser suggests that, 'the museum's public consultation process and its incorporation of exhibitions of local black artists had been ground breaking in its inclusivity' (2009, p.235). 
The exhibition was part of a wider programme 'Abolition 200' which took place in Bristol. Dresser comments that the programme was both engaging and contested (2009, p.231): there was 'deep suspicion expressed in some quarters that the bicentenary of the abolition of the slave trade would be misrepresented by official bodies and made into a Eurocentric vehicle of selfcongratulation' (Dresser, 2009, p.231). The museums engaged in the 2007 commemorations were necessarily implicated in national cultural policy which struggled with the difficulties of the issues. In their analysis of Tate Britain's programme for 2007, Dewdney et al highlight one of these difficulties:

'However well-intentioned government attempts to link the events of 1807 with questions of racial inequality in 2007 were, the linkage between the two timeframes defined by a narrative of transatlantic slavery and individual subjugation inflected the same narrative of victimhood on a contemporary diverse population simply on the basis of racial difference, exacerbated by the targeting of BME audiences, and thereby invariably enhancing the idea of racial difference and marginalisation.' (2013, p.67)

In response to these changing demands, many museums today adopt a wider remit than that of collecting, conserving and displaying artefacts and specimens (Bennett, 1995; Message, 2006). Of particular relevance to this essay is the shift that Arnold-de Simine identifies from 'history museum' to 'memory museum' (2012, p.15; Arnold-de Simine, 2013). This marks a shift away from the museum as the authoritative narrator of a progressive national narrative to one that invites affective responses. 
Such a shift is particularly relevant in the case of the abolition exhibitions. However, Wilson argues that the exhibitions deferred 'a confrontation with a traumatic past' and in fact repressed it (Wilson, 2010, p.176). According to Fouseki, some of the consulted community groups 'often experienced frustration, anger, and disappointment during and after the development of the 1807 exhibitions' (Fouseki, 2010, p.180; see also Cubitt, p.2010; Waterton, 2010). These commentaries are echoed in some of the entries to the Visitors' Book from the Breaking the Chains exhibition:

As an African American female, I am overwhelmed with a number of disheartening emotions. I move from sadness to anger in a swift movement of the eye. Are you celebrating African culture or are you subtly defending the institutions of slavery because of its profitable advantage? I'm extremely confused by the intentions and the purpose of this museum... (Breaking the Chains, Visitors' Book)

For this visitor, the exhibition's narrative failed to express the reality of the trauma behind the story, to such an extent that the writer thinks the exhibition might even be condoning slavery. Such alienation can arise when visitors find nothing to suggest the exhibition makers have any sense of what their experience might be. She is left alone with her experience. Later in this essay, we discuss how Social Dreaming may contribute to generating a shared affective space for visitors to a potentially traumatic museum experience.

Much museological analysis focuses on art museums and what they do with and to art (Hetherington, 2006; Preziosi and Farago, 2004). Critique of the representation of history in museums often takes place within a theoretical framework of memory, emotion and identity 
(Arnold-de Simine, 2012). This interest in emotion has arisen alongside a museological and practice-based interest in 'difficult heritage' or 'dark history' (Macdonald, 2009; Witcomb, 2013), dealing with subjects like war and genocide. Some such museums express a particular sensitivity to the subjective experience of people caught up in the history and that of the visitors (Smith and Campbell, 2015; Pivnick and Hennes, 2014; Gould, 2011).

In her analysis of the commemorative exhibitions Smith concludes that the powerful emotions that accompanied the exhibitions

should not have been ignored by curatorial staff. Rather it is important to recognise that such emotional issues exist and to develop the tools or opportunities within an exhibition to help visitors constructively mediate them. Providing such resources may help to challenge strategies of disengagement and avoidance and should be considered as an integral aspect of any attempt to recall and exhibit dissonant heritage and history. (Smith 2010b, pp. $209-10)$

Although we agree that emotional issues may not have been addressed, we believe that rather than deliberately ignoring such issues, most of the museums were engaged in common museum practice whereby collections are used to present a history derived from a written narrative. In this context, the collections are used to illustrate and the evocative powers (Bollas, 2009) of the objects themselves not overtly addressed. Any emotional vibrancy within the illustrated narrative of the exhibitions was not explicitly made available for the audience to process. 
The growing critical literature about museums as places of emotion and affect (Smith and Campbell, 2015; Shelton 2006) arises from this need. The essay develops a psychoanalytic perspective within this discussion, an unusual stance for museum or heritage studies. In taking such an approach we are not surprised by the complexity of emotions that the exhibitions evoked. Our contention is that psychoanalytic theory brings an understanding of contradiction and irrationality, and the psychic and cultural origins of emotion, that makes it particularly apt for dealing with the subject of slavery and the conflicting emotions evoked by the 2007 commemorations. Our focus then is on psychosocial theory and the interpretation of the contributions to the Social Dreaming workshops at the BECM, rather than an exhaustive analysis of other kinds of data that has already been used in extensive research into the 2007 commemorations (for example see Smith et al, 2011). Also relevant but beyond the scope of this essay is the literature on museums as sites of memory and indeed the 'new museology' which discusses, amongst other things, the concept of the memory museum (eg Macdonald 2013;

Shelton 2006; Andermann and Arnold-de Simine 2012; Dewdney, 2013; Araujo, 2012).

We see Social Dreaming, therefore, as a way of introducing an alternative emotional and affective perspective on what a museum might offer its visitors. Our hypothesis is that the use of Social Dreaming enhanced the expression and understanding of the hidden emotional communications that were implicit in the narrative of the exhibition.

\section{Social Dreaming: Visualising Emotions in the Museum}

This then was the context for the Social Dreaming workshops. They questioned the thesis of the 1807 commemorations that it was time to 'move on' (Waterton, 2010), which at the time of 
writing is still the UK Prime Minister's official response (Andrews, 2015). To borrow from Arnold-de Simine, the workshops encouraged 'an imaginary engagement with the past as an intractable "other" that cannot be brought to a closure' (2012, p.30). They were a subtle intervention but one that brought a significant additional dimension to the workshop participants' experience of the exhibition. They were both an actual and a symbolic intervention (Brown, 2004, p.247) into a contested area using dreams and visual material that acknowledged the profound and complex impact of a traumatic history. It made the museum, albeit for a short time, a place where complex emotions were expressed, and unconscious responses were understood to be influential in determining visitors' experiences.

Social Dreaming is a way of sharing and processing complex emotions, especially those that are difficult to express because they are traumatic or disturbing. The method is particularly useful in bringing to light affect around difficult topics that might otherwise be avoided (see for example the use of Social Dreaming in the context of the Israeli-Palestinian conflict, Biran, 2007; or in post-apartheid South Africa, Hahn, 2007). Typically, participants gather in a room and share dreams and associations for 60-75 minutes, and then follow this up with a discussion that may last 30-45 minutes. The emphasis on the sharing of emotions comes through the dream images and associations to those images because dreams 'insist with greater energy upon their right to be included among our real mental experiences in respect to their affective [sic] than in respect to their ideational content' (Freud, 1991, p. 595). Since the mid-1980s Social Dreaming has been used as a means of both uncovering and discovering hidden or unspoken thoughts, the 'unthought known' (Bollas, 1987), and emotions in participatory settings (Lawrence, 2005; Manley, 2014). During the dream-sharing event, called a 'matrix', dreams are not initially 
interpreted or given explicit meaning by the facilitators or researchers. Instead, the dream images and associations are allowed to gradually accumulate. The sensation is of complex emotions emerging in such a way that participants often feel they are perceiving new thoughts and meanings. This process is immediately followed by a dialogue and reflection on the images and the emotions so that participants can give sense and meaning to the Social Dreaming work.

The extensive literature that documents the use of Social Dreaming (for example, Lawrence 1998; 2005; Clare and Zarbafi, 2009; Baglioni and Fubini, 2013; Manley, 2014) has highlighted the method's potential for engaging with complexity through people's dreams and a shared 'associative unconscious' (Long, 2013), that is to say the sharing of unconscious material through dreams and associations to those dreams by a group ('matrix') of people who come together specifically for this purpose. The idea of the 'associative unconscious' draws from Freud's (1900) use of free association with his patients. In Social Dreaming, however, the free association occurs in a shared and non-therapeutic setting. In the matrix the associations of thoughts, feelings and ideas are understood as being common to the social world of the participants. The matrices work to simultaneously encourage participation and sharing and a certain de-personalising of the themes, image and emotions that emerge. That is to say, in the course of the matrix, we are interested in 'the dream and not the dreamer' (Lawrence 2005, p. ix). This is why the seating is arranged in a 'snowflake' pattern, as illustrated below. 


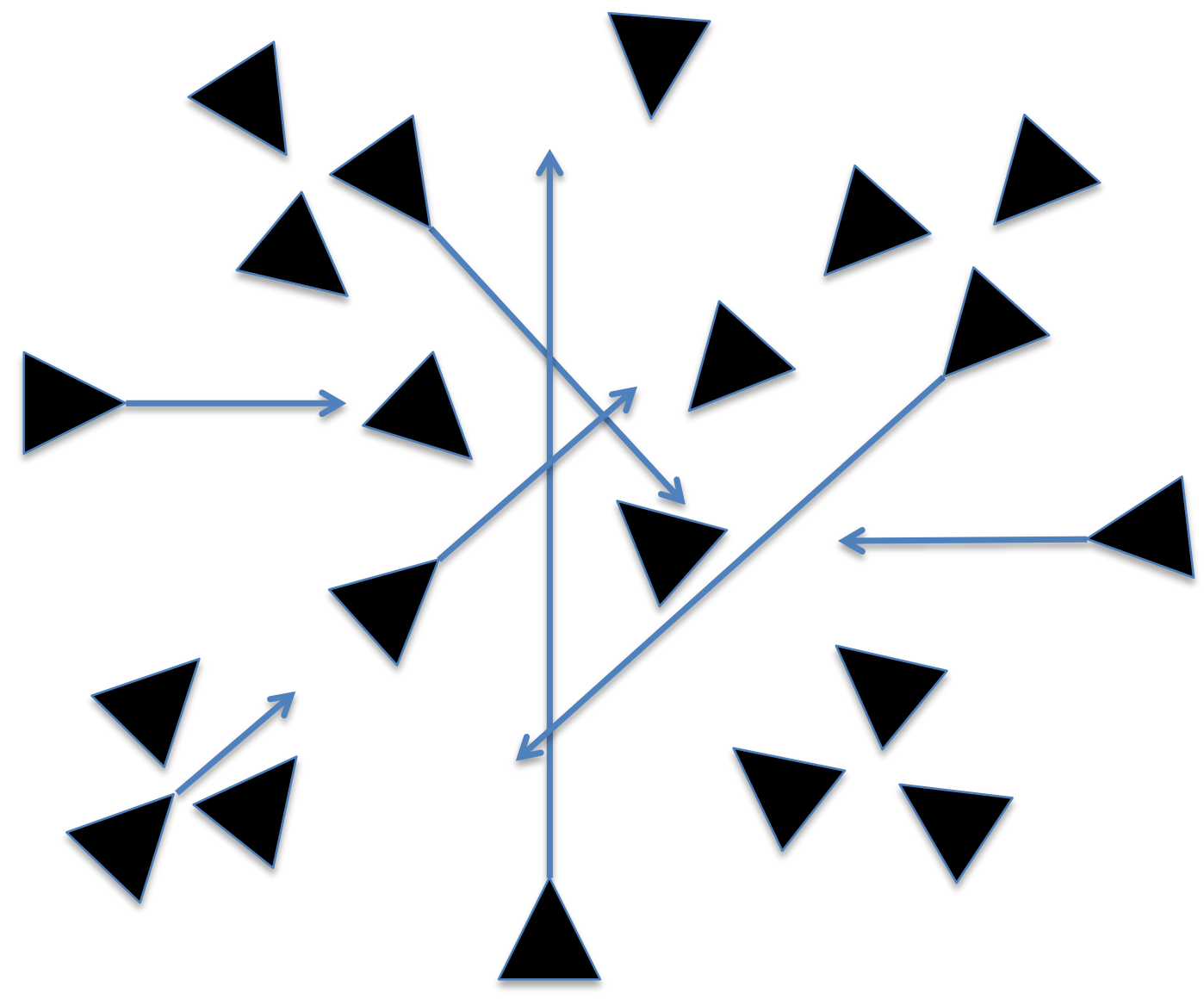

Figure 1. Snowflake pattern

This configuration makes it impossible for a participant to directly face others and allows him or her to speak 'to the matrix' rather than to any person in particular. This is important in engendering a non-judgmental, non-interpretive atmosphere. It also stimulates the creation of a new shared space that resonates with the concepts of potential space and transitional phenomenon developed by D. W. Winnicott (Winnicott, 1991 [1971]; Kuhn, 2013). As Kuhn says,

'... in potential space an individual can engage with the (external) inherited tradition whilst bringing something of their own inner world to it, both drawing upon and feeding into a personal style or idiom' $(2013$, p.5) 
This is a space between inner and outer worlds for both fantasy and reality, where the creative imagination can flourish.

The purpose of the discussion that follows the sharing of dreams is to unravel the collage of images and feelings that has been expressed in the matrix and to give meaning to the work. Notes are taken both of the matrix and the discussion that ensues. The researcher applies the idea of 'working hypotheses' throughout the process, so as not to foreclose meaning and interpretation during the process itself. By 'working hypothesis' we understand an acceptance of 'approximate reality' (Manley, 2014, p. 336). The concept is discussed at length by Long (2014). The interpretation, which begins in the post matrix discussion, depends on making interconnections and relationships between the dream images and associations, which may be seen to exist either within a single matrix or, as in the case of the present case study, from matrix to matrix.

The validity of this process as applied to the Breaking the Chains exhibition has already been generally discussed by one of the authors (xxxxxxxx). In that study, some important images and themes from the matrices were applied to the exhibition in the BECM. Our current study takes a single detailed example of the development of a dream image - that of the boats and ships during the course of the four matrices and demonstrates how interpretation of meaning can emerge by making connections between the images that emerged and re-emerged from matrix to matrix. 
There was a lengthy negotiating process with the museum's outreach staff about the nature of the workshops and a certain initial reluctance to give permission for an event that might give the museum a bad press. But as a result of the museum's desire to collaborate with local communities it was agreed to hold four workshops. Participants were recruited from the museum's mailing lists, personal contacts and on an ad hoc basis as visitors arrived in the museum. They were asked to visit the exhibition at least once before attending the sessions. The workshops took place during the normal museum opening times and lasted about two hours. Between 15 and 25 people took part in each session. The matrix was transcribed and distributed to participants soon after the event. This provided both a record and data for later analysis. It also gave the participants a further opportunity to reflect upon their experiences.

The recurring image of a boat or ship freely emerged from a combination of the exhibition experience and the Social Dreaming sessions. The emergence of this image resonates with, and maybe corroborates, John Beech's assertion that 'slavery (really the slave trade) is often defined and interpreted as a "maritime activity"; that is, as a subset of transport history or the expansion of British trade' (quoted in Oldfield, 2007, p.135); in other words, almost as a way to avoid confronting the essence of slavery itself: the black Africans inside the ships. The choice of this image by participants in the workshops maybe suggests a similar avoidance of British responsibility for slavery in an exhibition housed in the British Empire and Commonwealth Museum, that was indeed being defined in terms of British colonial trade and its ships: 'Britannia rule the waves', 'Britons never, never, never shall be slaves'. The confusion of the abolition of the slave trade with the abolition of slavery may constitute a national avoidance of responsibility that is still being debated today even in the face of the mounting evidence of the widely shared 
participation of a great number of white British ancestors in the slave trade and the acceptance of financial compensation for their 'loss of property' when the slave trade was eventually abolished, while the black slaves themselves received nothing (Hall et al, 2014).

Our reflection on the development of this image in the minds of the visitors to the exhibition begins with the Visitor's Book placed at the exit of the exhibition. We use this image as our transitional point as this exit was also the threshold from the exhibition to the Social Dreaming session.

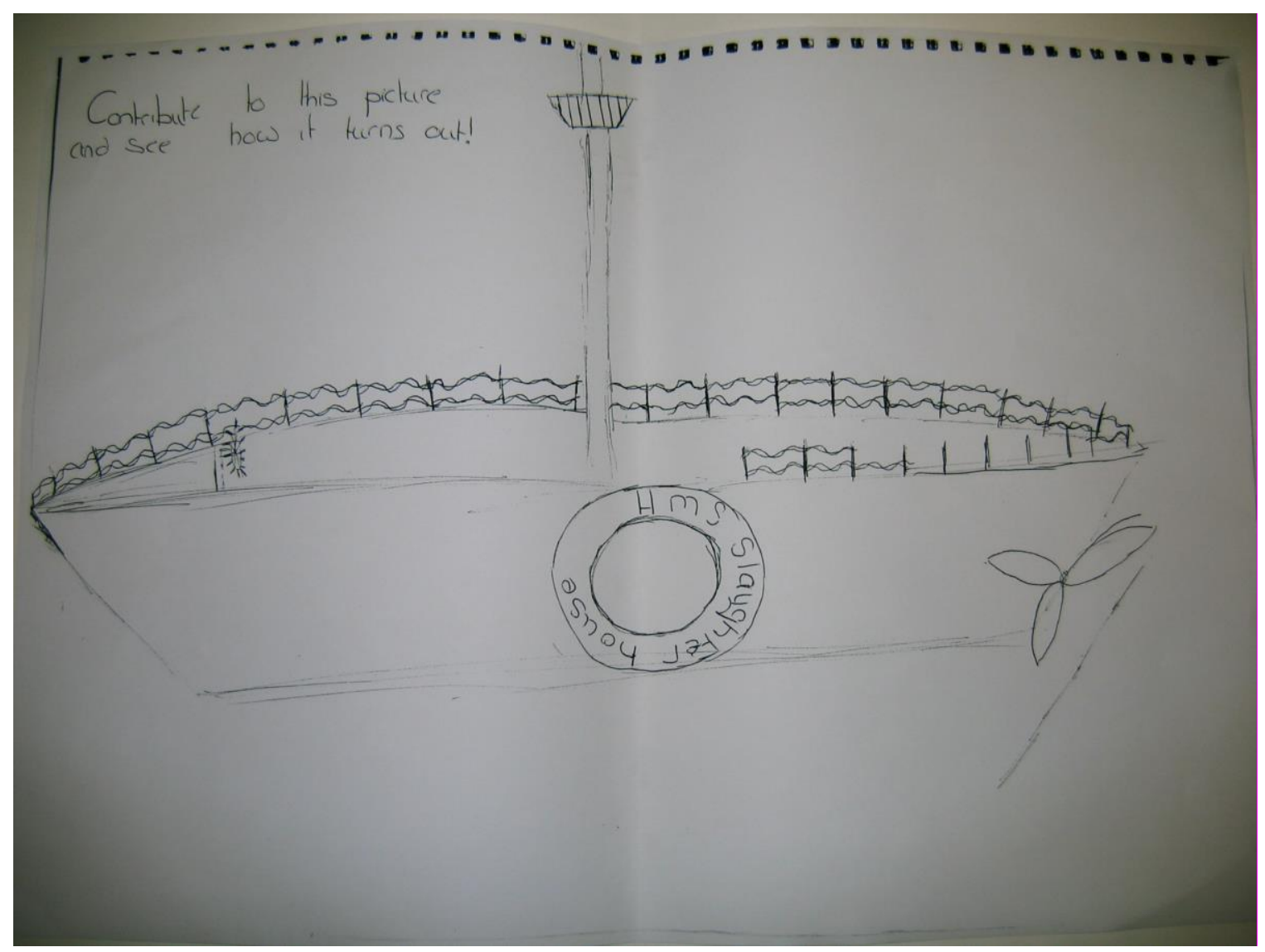

Figure 2. Visitor's Book: Slave ship 
In contrast to the written entry quoted above, ( page $\mathrm{xx}$ ), this contribution is sparing with words. The name on the boat's life buoy is 'HMS Slaughter house' and we are asked to 'Contribute to this picture and see how it turns out!' These words are carefully chosen to emphasise the truth behind the 'maritime façade' by naming the ship as 'His Majesty's Ship'. At the same time 'Slaughter house' written in two words with the effect of highlighting 'house' reminds us both of what is 'housed' in the hold of the ship and of the British 'houses' back 'home' that contribute to the slaughter of people. The word 'slaughter' conjures up the less-than-human treatment of black slaves. These words are part of the image, ensconced as they are within the life buoy. The other words on the page serve to invite us to further contribute to the image, deliberately directing us to 'think visually' and draw. Even without adding to the drawing, anyone who comes across the image can complete it in his or her mind's eye. In asking ourselves why this contribution should be drawn rather than written, we suggest that maybe the drawer is using the image to digest the traumatic experience of the exhibition and that this contrasts to the previous entry from the Visitors' Book quoted above. The power of the drawing of a ship in the same Visitors' Book arises partly from the lack of historical narrative, the very narrative that was so frustrating to the writer of the previous entry. The drawing is both representative of the images in the exhibition and the emotion within the image itself. It encapsulates a multi-layered emotional struggle with the meanings of the exhibition, where the outside of the slave ship and its association to maritime glory and imperial power hides a 'dirty secret' inside, with the consequent feeling of repressed guilt and the potential for reparation The drawing thus provides clues as to why the image of the boat or ship was echoed repeatedly in the Social Dreaming workshops. 
The picture of the ship's hold (Figure 3) in the exhibition was an image that caught the attention of participants in the workshops.

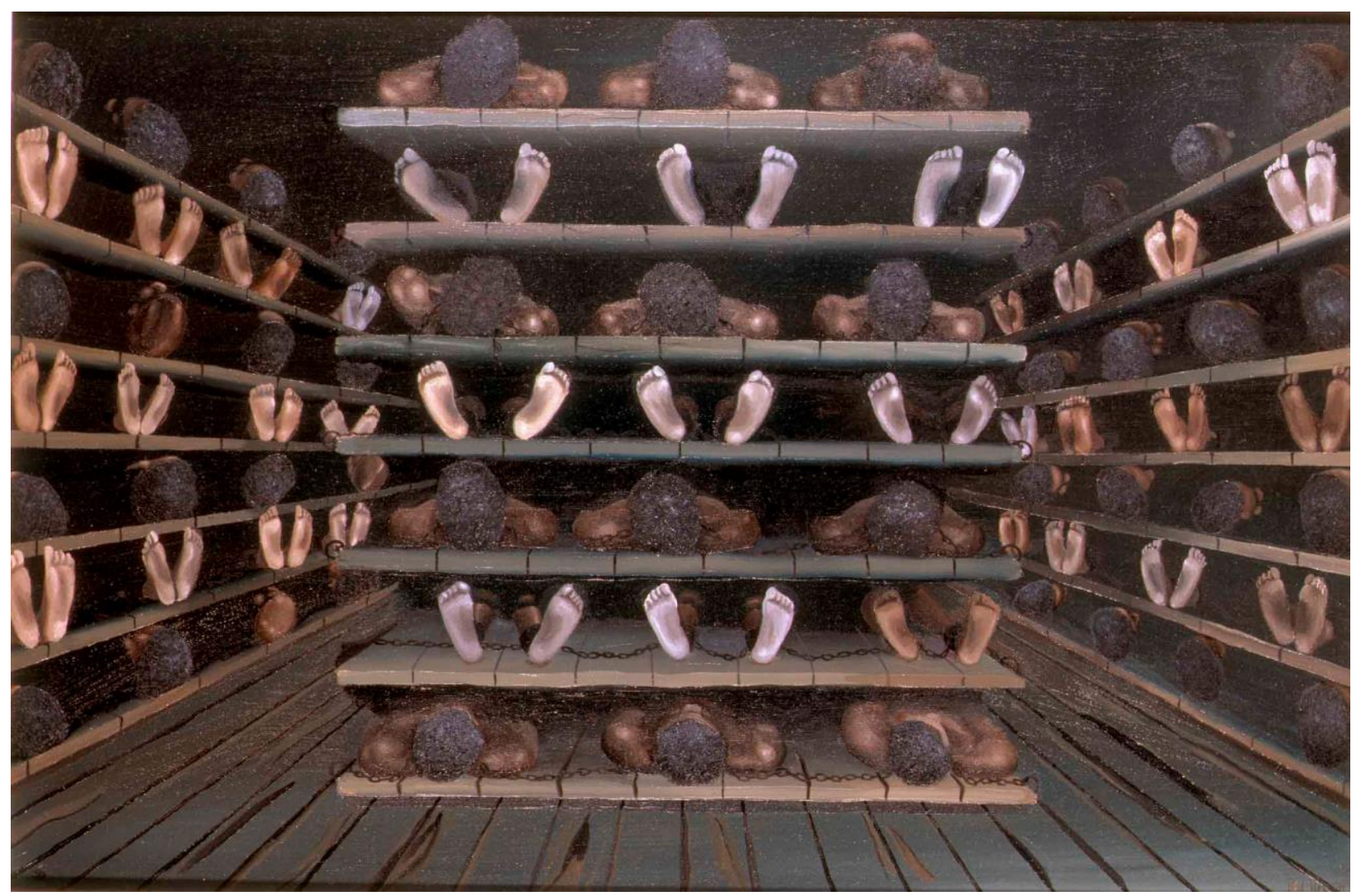

Figure 3. Slaves stacked up in the ship's hold (Sheol by Rod Brown)

The image was powerfully displayed at the beginning of the exhibition as a life-sized panel. In this way, the visitor was invited into the exhibition by going inside the slave ship. Although the initial shock of such an image may well diminish as the visitor moves away, this particular image continued to resonate with the participants in the 'inside/outside' fashion described here:

The sounds outside give me the feeling of being condensed into a small space, reminds me of the pictures of slaves stacked up. You can see the soles of their feet. You can hear the sound of the ship's engines in the exhibition, like the sounds from outside... 


\section{(Social Dreaming Workshop)}

The participant expresses the anguish of claustrophobia, as if they could empathise with the actual sensations of the slaves, as expressed through a powerfully conjured imagination which is sensually constructed to include sight and sound. The participant is able to move from cognitively registering the archival record of 'pictures of slaves' to a sense of personally and emotionally 'seeing' the 'soles of their feet' and 'hearing' the sounds of the ship's engines. It is almost as if the inside of the slave ship - presented to the visitor as a life size introduction to the exhibition - has provoked an 'inside' reaction, the inner emotional response of the visitor, and it is this 'inside' that is expressed through the forum of Social Dreaming.

The matrices developed this sense of claustrophobia into an exploration of fear, with the unreality of the unknown space of the ship's hold being compared to a 'scary dream' and the quality of this fear being summed up in an image of the Titanic and associations of tragic doom. In the first Social Dreaming matrix, the relevance of this expression of affect was emphasised through a comparison with the news reports of modern day perilous boat journeys of immigrants from Africa:

Reminds me of a newspaper headline in Spain concerning the black Africans who try to cram into tiny boats and make a trip to Spain, the Canary Islands to find freedom... Wonder what the difference is between the slaves 200 years ago and those people today... 
This example demonstrates the movement in Social Dreaming from the suggestion of the dream image to the association of the present day crisis, and how sharing a dream image is able to induce affective understandings that are relevant to the participants in the matrix even if the historical event in the recounted dream, for example the sinking of the Titanic, is located in the past and in some virtual reality in the imagination of an individual dreamer. In this way, the dream becomes relevant to all the participants in the matrix and contributes to a shared understanding of the affective realities of the exhibition buried within the exhibition narrative.

These guiding associations to the dreams and the images in the exhibition may also be stimulated by art, culture or literature. In the following example from the second session, the cruelty of humans against humans is evinced in a reference to Heart of Darkness (Conrad, 1995 [1902]):

When I came here I picked up a book in the shop, Joseph Conrad's Heart of Darkness...and reminded of the dark corridor, the stacks of slaves, like a dream scene, the image stayed with me. Where is the darkness? Who are the slaves? Who is responsible?

In this case, the participants who have read the novel will to some degree 'relive' the sensations of the book and understand how those sensations are also evoked by the fate of the slaves. Even if a participant has not read Heart of Darkness, there are plenty of clues in the association of the book to the exhibition that guide each participant to an open confrontation with affect and the question 'where is the darkness?' These 'clues' can be felt by each participant through 
associations to darkness, heart-felt emotions and links to the image of the slaves in the hold of the ship from the exhibition.

Another feature of Social Dreaming is how that which in another context might be unnoticed as a throwaway comment, even a cliché, takes on significance as a result of the accumulating collages of images in the matrix. In the third session, for example, we are told 'We're all in the same boat', which in the context of the accumulation of dream images and associations to boats and slave ships becomes a way of identifying with the slaves in the ships and breaking down the barriers between them and their masters and also with the participants in the matrix. In the third session, this suggestion leads to a complex contemplation of the possible meanings behind the directions adopted in a rowing boat:

Actually, the right way to row a boat is facing backwards. Still, it's necessary to have someone there who knows the direction, not just staring in the right direction.

This reflection suggests the paradoxical feeling of having to turn your back to your destination in order to row a boat. This sense - of not knowing where you are going and yet the necessity of this ignorance to make 'progress' to our destination, the unspeakable hell of an enslaved existence - is expressed using a form of what Freud called 'condensation': the ability of an image, especially a dream image, to condense multiple meanings within an image (Freud 1991, pp. 383-414). As a result of this condensation within the matrix the emotional content is made more complex and turned into an affective rather than simply emotional experience. 


\section{Social Dreaming and affect}

To help us define the value of the Social Dreaming work in the BECM it is necessary to make a distinction between an 'emotion' and 'affect'. We use the word 'affect' rather than 'emotion' when discussing shared emotional complexity because the dreams and images encourage a sense of knowledge through complex embodied feeling. Unlike emotion - which for our purposes we can define as recognisable, finite and nameable feelings such as 'sadness' and 'happiness' affect is difficult to define. Indeed, within this difficulty we already have a clue to the connection between affect and the dream image.

The Social Dreaming matrix is expressive of emotions, reflections and the affect contained within dreams. In fact, many of the emotions, as defined above, and the subsequent reflective thoughts in the matrices arise from the ill-defined images of dreams and associations where affect resides. For example, a thinking reflection from a participant such as 'everybody needs to co-operate' emerges from the affective sensation of being chained down in a ship's hold, 'not being able to determine direction' and having 'to always lie on your back with no space to turn around'. These images both embody and trigger affective sensations that in themselves cannot succinctly be described as an emotion. But it is this immersion in the original affect of the images that encourages the subsequent reflective and emotional expressions. Although such expressions arise from the original affect that forms part of the images, the original raw affective state of these images must remain if the authenticity of our understanding of the slaves' realities is to endure. The direct expression of emotions and reflections in the Social Dreaming matrix is indissolubly linked to the more complex affect of the images. The expression of an emotion such as being 'moved' - 'I found that image very moving' - would be painfully inadequate if it 
had not been preceded by the description of affect embodied in 'being trapped in a ship, away from the known world, like a scary dream, not being able to see out, like the Titanic'. In this extract, apart from the instant recognition of affect that we have upon imagining a 'scary dream', we are presented with the image of the Titanic and all the sensations that go with it: hopelessness, helplessness, terrifying fear, a closing in of death by drowning, human hopes and desires crushed; cruel twist of destiny and fate, a journey curtailed, and so forth. All of this together is complex affect encapsulated in the single image of the Titanic.

'Affect' has been used in different ways, but our use of the term is Deleuzian, (see Thrift, 2008 for a discussion of the various uses of the term 'affect'). For Deleuze, affect - adopted from Spinoza's affectus (Deleuze, 1978; Spinoza, [1677] 1992) - is a holistic, embodied form of complex emotional responses occurring in tandem with another or others, animate or inanimate, that are in a process of constant motion or stirring - 'becomings' - with each other. The key to how and why this occurred in the Social Dreaming sessions lies in comprehending the development of affect within a web of inter-relations between the participants and also between each of them and the exhibition. Through or behind the historical narrative of Breaking the Chains, the visitors experienced layers of disturbing emotions that were not acknowledged. The Social Dreaming sessions provided a contained, safe space for exploring the complexity and difficulty of this affect.

Precisely because affect is difficult to define it may be better expressed through images. These can take a variety of forms, some being closer to an acknowledged reality than others such as the real images in an exhibition, and images in the mind's eye. These are more than representations 
located in the time-bound historical narrative of the museum and presented to the audience as such. Even as past objects they are witnessed in the present and may also be connected to some distant or close memory. For example, the 'past' image of the slaves in the hold of the slave ship became the 'present' image and affect of the participants in the Social Dreaming 'locked' inside a 'wooden' room:

I was struck about coming through the door here and the door being locked behind us, a sense of claustrophobia...like in the ships, being left here but in this case we're in a gracious Jacobean room.

For Henri Bergson, who was an important influence on Deleuze, images are never 'pure perception' but 'memory images', where the present is always inextricably combined with some form of recollection (Bergson, 2002, pp. 124-135). Similarly, dream images are memories that become present through the sharing in the here-and-now of the Social Dreaming matrix. In this sharing, there is also a sharing of the affect held within those images. As these images and affects accumulate in the course of the process of the matrix, the affect becomes increasingly complex. For example, feelings of guilt and shame were brought out by the various transformations made available through the images that were associated to wood. These included the wooden hull of the ship made of logs; the logs tossed into the sea to measure the distance from freedom to slavery, (a reference to measuring a ship's speed by throwing a log tied to a knotted rope into the sea, the knots being counted as they passed through sailors' hands to calculate the speed of the ship); the ship's log (though not wooden) recording the slaves' journey and made present through association with email; and finally the possibility of death, people as 
floating logs, and the cynical thought of recycling the 'dead' logs into fuel, and with this image, the dehumanising of the slaves.

These complex multiple affects that are shared in the Social Dreaming are connected to and by the dream images. In this way, the dream images - and therefore the affects - are processed in the real-time of the matrix in an active relationship between all that is perceived and the perceiver, and vice versa. Although to some extent this is true of all perception - an object in an exhibition cannot really be perceived out of its context - a conventional exhibition will often use an object as evidence or illustrative of a fact, in other words it is removed from its original context and is isolated within the scientific condition of the exhibition. This is how an exhibit might exhibit a fact rather than affect. Through Social Dreaming, however, the images become intimately bound to the complex emotional realities that join the perceiver and the perceived and the containing environment of that process. In this way, the Social Dreaming process creates images that are affects: the 'image-affect' (Manley, 2009, pp. 84-85).

These image-affects sometimes work in isolation, like symbols that represent phantasies and unthought knowns, (Bollas, 1987), such as the example of the Titanic above, but very often they express complexity through a combination of the image-affects in relation to others. This leads to a 'collage' of image-affects that create potential meaning(s). The greater the collage the less stable the specificity of meaning and the richer the combined affective potential. This is because the various meanings of the collage may change and shift according to which combination(s) of image-affects one can perceive in any particular moment. This may also be different from one person to the next, so that different participants in the Social Dreaming matrix might understand 
different meanings from the collage but still be in agreement that these multiple meanings create a 'sum that is greater than the parts', to use a well worn, but still relevant, phrase from systems thinking. For example there was an image of Jonah being trapped in a whale which connected with that of the Titanic:

Being trapped in something, like a ship or a crocodile reminds me of Jonah being trapped in the whale...

In this way, the Titanic becomes more than a single expression of affects in isolation from other images, even though in this image alone these are already rich and multiple. By merging the whale and Titanic images, the sense of doomed fate of the Titanic and of being drowned within its hull connects to the idea of divine punishment within the belly of the whale leading to a complex sensation of affect whereby the combined fates of the Titanic and the whale seem indescribably unfair and at the same time tinged with a faint hope of divine redemption, so faint it is both desired and cruel, while the idea of being swallowed by a whale continues to be monstrous.

This new knowledge is gained through these affective communications of accumulating, collagelike complexities. Instead of identifying meaning through representation and symbol, the participant to the Social Dreaming matrix identifies him or herself with the changing elements of the image-affects in order to understand meaning through affect rather than through the mind's intellectual cognitive process. 


\section{Becoming, the depressive position and reparation}

The understanding generated through affect emerges through the experiential process of 'becoming'. Participants in the Social Dreaming Matrix express affect in images that they can sometimes embody and 'become'. By comparing the 'becoming' in the Social Dreaming sessions, with Deleuzian (Deleuze and Guattari, 1988) accounts of 'becoming' - this term being inseparable from a Deleuzian understanding of affect - one becomes aware of the participants' image-affects. For example, in trying to imagine what it must have been like to be trapped in a slave ship, the participants gave a sense of what, following Deleuze, we might call 'becoming crocodile' and then 'becoming Jonah in the whale'. The image of the crocodile initially emerged from a dream of a child being eaten by a crocodile - 'There was a little girl by the water and suddenly the crocodile took her. You could hear her screaming in the belly of the crocodile'. The memory of this image resonates in the subsequent image of being swallowed by the whale. In their book A Thousand Plateaus, Deleuze and Guattari used similar 'becomings-animal' - the becoming whale and crocodile - in order to illustrate the philosophical concept of 'becoming' (1988, pp. 243-248). The fact that these same animals were used by Deleuze and Guattari as examples may indicate a particular archetypal power carried by such creatures which, independently of Deleuze and Guattari, emerged in the Social Dreaming. We have no space to develop this idea in this essay. However, Deleuze and Guattari continue their line of thought by saying that these becomings occur on the fringes of experience where the 'sorcerer' rules (Deleuze and Guattari 1988. p. 246). This also seems relevant to the Social Dreaming experience. What they mean by this is that through the embodied imagination (the place of the 'sorcerer'), where 'the anomalous is the borderline' (1988, p. 245), apparently disparate entities can join and interconnect. In our example, the fear that we associate with the image of being 
eaten by the crocodile is combined with the sorrow and repentance of Jonah inside the whale and the fate of the slaves inside the 'belly' of the slave ship. The affect is the combination of this fear, sorrow and repentance expressed in the images. In the Social Dreaming sessions the participant is 'becoming-animal' as a means of expressing affect, imaginatively eaten by the crocodile and swallowed by the whale. Through imagination and felt affective experience, the participant can come closer to understanding being trapped inside the hold of the slave ship, which might otherwise be difficult to conceptualise. This sense of 'becoming' is what enables the disparate combinations or image-affects to be experienced by each participant in Social Dreaming.

The state of mind required of the participants in order to embody affect through this process of becoming needs to be expansive and able to receive and synthesise multiple potentially contradictory ideas. This state of mind is akin to the Kleinian depressive position. Although a suggestion that we consider Deleuze and Klein as mutually connected might at first appear to be unusual, Deleuze was influenced by Kleinian thought (Widder, 2008). According to Widder, the 'twist' that Deleuze brings to Klein involves 're-reading her story of pre-Oedipal and Oedipal development by placing the infant in a world of simulacra rather than one of substantial objects with stable boundaries. The world of simulacra is no longer a temporary one that the infant outgrows, as it was for Klein, who saw the infant synthesizing part-objects into whole and complete objects as its ego developed.' (2008, p.2) It is with this reading of Deleuze in mind that we see the affective response of the Social Dreaming as being situated in the process of the matrix, that is to say in the simulacra of the shared dream worlds of the participants. 
We have already discussed how the exhibition tended to provoke an intellectual confusion about the meaning and purpose of Breaking the Chains. The Social Dreaming created an affective space for the transformation of intellectual opposites into an emotional unity. Such a view of the workshops suggests that the acceptance by the participants of the negative emotional realities of the slave trade, the 'depressive position', leads to a potential for reparation. In the case of the slave trade and Bristol, this could have been the reparative value of an apology for the city's participation in the slave trade, as was being debated in the city at the time of the exhibition. We suggest that participation in the Social Dreaming made apology more relevant and reparation more possible through each person's personal experience of affect.

The debate within Bristol about an apology was part of the wider reparations discourse taking place at the time, and still today (Beckles, 2013; Coates, 2014). The museum hosted the local apology debate in May 2006, which was chaired by the anti-apology philosopher A.C. Grayling. The apology debate is in part about whether a symbolic gesture is sufficient. Kaufman argues that 'critics who simply equate the slavery reparations campaign with a perverse wallowing in victimhood demonstrate a profound disregard for the symbolic need for both the making and the accepting of reparative initiatives (2007, p.275). Financial reparations, as promoted for instance by the Caribbean Reparations Movement (Rojas, 2014) are seen to be more genuine since they would require considerable outlay from former slaving nations. The publicity given to the Legacies of British Slave Ownership project at University College London has fuelled the reparations movement (Best, 2013; Hall et al., 2014; Legacies, 2015) 
Will Kaufman (2007) has discussed the psychology of Kleinian reparation as an essential aspect of slavery studies. He emphasises the symbolic and psychological need for reparation as opposed to financial reparation, and reminds us that for Klein reparation was a creative act: 'Klein herself argues that all creative work springs from mourning, and that all creative work is by definition an act of reparation.' (p. 278). This would seem to be especially relevant to our study of Social Dreaming to process the horror of the trans-Atlantic slave trade. The engagement with creativity that is often felt by participants in Social Dreaming has been extensively commented in a book dedicated to that area (Lawrence 2010). In this essay, we are further suggesting that Kleinian reparation can be achieved through an involvement with the affect created by working in the Social Dreaming matrix. Kaufman warns against 'mock reparation' an example of which he sees in American civic memorials where 'mourning is denied and historical guilt is turned into historical triumph' (2007, p. 279). That is to say, the 'bad' aspects of slavery are denied in favour of the 'good' that came out if it, and feelings are split into dualities. Similarly, the Breaking the Chains exhibition may have been focused on the 'mock reparation' of the triumph of the Caribbean slave revolts that appear to be placed at the end of the exhibition to somehow make up for the failures of humanity in the rest of the display.

Museums conserve and protect from destruction a nation's treasured objects. As such they can be psychoanalytically conceptualised as places of reparation, as a nation's source of redemption from the destruction carried out through war and neglect (Trustram, 2013, p.198). If trauma creates knowledge (Alford, 2014) then museums have the opportunity to create the circumstances for such knowledge to be accessible (Hetherington, 2006, p.598). The 2007 
exhibitions went some way towards this. The Social Dreaming workshops began to explore the ways in which such knowledge might not be available even to the knower.

In this 'unknown' way, the historical and factual approach to the exhibition could be interpreted as a curator's defence against the painful emotions that the exhibition was bound to stimulate. Bristol is a city whose wealth was partly built on slavery and so it is not unreasonable to suppose that this defence resonated with many of the visitors. This was also a reflection of the need for a wider societal or national defence against the shame of the slave trade, hence the emphasis on abolition. The subject of the slave trade itself invites divisions and splitting: black and white, good and bad, master and slave, then and now, them and us, and so on. In the example of the Visitors' Book entry by the 'African American female', this splitting and tendency towards the paranoid schizoid position was acutely felt as a result of the exhibition experience 'overwhelmed with a number of disheartening emotions. I move from sadness to anger' - where the anger is partly a frustration at being 'overwhelmed' with emotions that have not had an opportunity to be aired. The implication in this entry is that the curators (and maybe it is assumed that they are white, not African American) are all 'bad' in their use of 'curatorial power' to simulate a 'colonial power' over black people and then, to make matters worse, leaves them to 'stew in their negative emotions', so to speak.

Leaving the exhibition in this state of paranoid schizoid sadness and anger, with its splitting of the museum and slavery as 'bad and powerful' and the African American as 'good and powerless', must have been, we suggest, an issue for many of the visitors. Indeed, the very title of the exhibition seemed to be directed at a celebration of the abolitionists who, unchained, 
'broke the chains' of others; and yet, at the same time, our feelings remain with those who were chained. If this is the case, we might consider whether this is because the mood of the exhibition was studiously historical, and that this stemmed any flow of empathic emotion that might have otherwise been achieved through the stories of rebellion. We suggest that the relationality of the Social Dreaming workshops and the ensuing dream space simulacra provided a potential space for the generation of affect leading to a Kleinian depressive position formulated together with others. This enabled the split of emotions generated by the exhibition - as the individual visitor confronts the exhibition on his or her own - to give way to reflection upon the emotions generated by the exhibition and their relevance to the contemporary lives of the participants.

\section{Conclusion}

One might argue that this essay has tried to define the ineffable in a context of the unknowable. That is to say, it is impossible to either conceive of or know the experience of the slave trade. And in discussing the possibility that the historical narrative of Breaking the Chains encouraged visitors to adopt paranoid schizoid positions, maybe we ourselves have been engaged in splitting: our 'love' of Social Dreaming and 'hate' of the exhibition. Maybe this essay is our attempt at reparation. Nevertheless, it seems to us, that there is something better-than-nothing happening here. The Social Dreaming workshops contributed to the practice of an evolving museum working with a community and sensitive to affect as well as persistent in truth-seeking. Maybe, too, this is relevant not just to museum practice but to ways of understanding how any institution might take people's individual and shared emotions seriously. We have shown that affective imagination can be stimulated by Social Dreaming and that this opened up avenues towards an expression of emotions that were stymied by the exhibition itself. The fact that this path towards 
affect is neither smooth nor without traps should not deter us from using Social Dreaming, or other related methods, in our attempts to understand the panorama of human experience that includes all our senses, as well as our endeavours to make intellectual meaning out of traumatic histories.

Brown comments that 'history shaped by traumatic violence becomes not a history that is recorded, explained, and resolved for all time but a history that is essentially not over' (2004, p.258). Whilst the 1807 Act did, in a sense, end the British slave trade, the Social Dreaming workshops demonstrate that its ending in another sense is indeed 'not over': the slave trade and its aftermath haunts the affective imagination. Gordon says that the ghost of something like slavery 'cannot be simply tracked back to an individual loss or trauma' (2008, p.183). This is what Social Dreaming makes evident: the public nature of an apparently privately experienced phenomenon.

Museums are cultural symbols of prestige and recognition so the location of the 2007 commemorative exhibitions in museums promised dignity and presence for the victims of the slave trade. But the museums took on an impossible task. They were caught between celebrations of the humanitarian actions of the abolitionists and mourning for the debasement of humanity through the trade in human lives; caught between hope and despair. Cvetkovich comments that 'the history of slavery presents the challenge of a missing archive, not only because of the generational distance but also because even in its time it was inadequately documented ...' (2003, p.38). We would suggest that the data from the Social Dreaming workshops can be conceived of as coming from a 'missing archive', an archive of the 
imagination. Cvetkovich goes on to say that traumatic histories like slavery demand 'unusual strategies of representation' (2003, p.38). Social Dreaming might be considered one of those unusual strategies.

\section{References}

Alford, C.F. (2014) Trauma and Forgiveness: Consequences and Communities. Cambridge: Cambridge University Press.

Andermann, J. and Arnold-de Simine, S. (2012) 'Introduction: Memory, Community and the New Museum'. Theory, Culture and Society. 29 (1): 3-13.

Andrews, K. (2015) Slavery. The Guardian 30 October, http://www.theguardian.com/commentisfree/2015/oct/01/britain-slavery-myths-david-cameronjamaica?CMP=Share_iOSApp_Other?CMP=Share_iOSApp_Other, accessed 30 October 2015.

Araujo, A.L. (2012) (ed.) Politics of Memory: Making Slavery Visible in the Public Sphere. New York and London: Routledge.

Arnold-de Simine, S. (2012) Memory, museum and museum text: Intermediality in Daniel Liebeskind's Jewish Museum and W.G. Sebald's Austerlitz. Theory, Culture and Society 29 (14): 14-35. 
Arnold-de Simine, S. (2013) Mediating Memory in the Museum: Trauma, empathy, nostalgia.

London: Palgrave Macmillan.

Baglioni, L. and Fubini, F. (2013) ‘Social Dreaming'. In Long, S. (ed.) Socioanalytic Methods. London: Karnac.

Beckles, H. (2013) Britain's Black Debt: Reparations for Caribbean Slavery and Native Genocide. Kingston: University of the West Indies Press.

Bennett, T. (1995) The Birth of the Museum: History, Theory, Politics. London: Routledge.

Bergson, H. (2002) Matter and Memory. In: Key Writings. London: Continuum.

Best, T. (2013) The case for reparations. The New York Carib News. 6 March. http://www.nycaribnews.com/news.php?viewStory=3672. Consulted 18 August 2015.

Biran, H. (2007) The dreaming soldier. In Lawrence, W.G. (ed.) Infinite Possibilities of Social Dreaming. London: Karnac

Bollas, C. (1987) The Shadow of the Object. London: Free Association.

Bollas, C. (2009) The Evocative Object World. Sussex: Routledge. 
Brown, T.P. (2004) Trauma, museums and the future of pedagogy. Third Text 18 (4): 247-259.

Clare, J. and Zarbafi, A. (2009) Social Dreaming in the $21^{\text {st }}$ Century. London: Karnac

Coates, T. (2014) The case for reparations. The Atlantic June 2014

http://www.theatlantic.com/magazine/archive/2014/06/the-case-for-reparations/361631/, accessed 30 October 2015.

Conrad, J. (1995 [1902]) Heart of Darkness. Hertfordshire: Wordsworth Classics.

Cubitt, G. (2010) Lines of resistance: evoking and configuring the theme of resistance in museum displays in Britain around the bicentenary of 1807. Museum and Society 8 (3): 143-164.

Cvetkovich, A. (2003) An Archive of Feelings: Trauma, Sexuality and Lesbian Public Cultures, Durham and London: Duke University Press

Deleuze, Gilles (1978) 'Lecture transcripts on Spinoza's concept of affect.' Source: http://www. webdeleuze.com/php/texte.php?cle=14\&groupe=Spinoza\&langue=2, (accessed 09.11.15)

Deleuze, G. and Guattari, F. (1988) A Thousand Plateaus. London: Continuum.

Dewdney, A. et.al. (2013) Post-Critical Museology: Theory and Practice in the Art Museum. London: Routledge. 
Dresser, M., (2009) Remembering slavery and abolition in Bristol, Slavery and Abolition: A Journal of Slave and Post-Slave Studies, 30 (2): 223-246.

Fouseki, K. (2010) 'Community voices, curatorial choices': community consultation for the 1807 exhibitions. Museum and Society, Nov 2010, 8 (3), 180-192

Freud, S. $(1909,1955)$ Analysis of a phobia in a five-year old boy. Standard Edition 10. London: Hogarth Press, pp. 3-149.

Freud, S. (1991 [1900]) The Interpretation of Dreams. London: Penguin.

Gordon, A. (2008) Ghostly Matters: haunting and the sociological imagination, Minneapolis, London: University of Minnesota Press.

Gould, L.J. (2011) Collective working through: The role and function of memorialisation. Organisational and Social Dynamics 11 (1): 79-92.

Hahn, H. (2007) Social Dreaming and the birth of South Africa's democracy. In Lawrence, W.G. (ed.) Infinite Possibilities of Social Dreaming. London: Karnac.

Hall, C. et al (2014) Legacies of British Slave-ownership: Colonial Slavery and the Formation of Victorian Britain. Cambridge: Cambridge University Press. 
Hetherington, K. (2006) Museum. Theory, Culture and Society 23 (2-3): 597-603.

Kaufman, W. (2007) On the Psychology of Slavery Reparation: A Klenian Reading. Atlantic Studies: Literacy, Culture and Historical Perspectives 4 :267-284.

Kuhn, A. (2013) Little Madnesses: Winnicott, Transitional Phenomena and Cultural Experience. London: I. B.Tauris.

Lawrence, W.G. (ed.) (1998) SocialDreaming @Work. London: Karnac.

Lawrence, W. Gordon (2005) Introduction to Social Dreaming. Transforming Thinking. London: Karnac.

Lawrence, W. G. (Ed.) (2010). The Creativity of Social Dreaming. London:

Karnac.

Legacies of British Slave - ownership (2015) https://www.ucl.ac.uk/lbs/. accessed 19 August 2015.

Long, S. (ed.) (2013) Socioanalytic Methods. London: Karnac.

Macdonald, S., (2009) Difficult Heritage. Oxford, New York: Routledge. 
Macdonald, S., (2013) Memorylands: Heritage and Identity in Europe Today. London:

Routledge

Manley, J. (2009) 'When words are not enough.’ In: S. Clarke and P. Hoggett (eds.) Researching Beneath the Surface. London: Karnac.

Manley, J. (2010) 'The Slavery in the Mind: Inhibition and Exhibition'. In: Lawrence, W. Gordon (ed.) The Creativity of Social Dreaming, pp. 65-83. London: Karnac.

Manley, J. (2014) 'Gordon Lawrence's Social Dreaming Matrix: background, origins, history and development'. Organisational and Social Dynamics 14 (2), pages 322-341.

Message, K. (2006) The New Museum, Theory, Culture and Society 23 (2-3): 603 - 606.

Oldfield, J.R. (2007) Chords of Freedom. Commemoration, ritual and British transatlantic slavery. Manchester: Manchester University Press.

Pivnick, B and Hennes, T. (2014) 'Managing Collapse: Commemorating September $11^{\text {th }}$ Through the Relational Design of a Memorial Museum'. In O’Loughlin, M. (ed.). The Ethics of Remembering and the Consequences of Forgetting: Essays on Trauma, History and Memory. New York: Rowman and Littlefield.

Preziosi, D. and Farago, C. (2004) Grasping the World: The Idea of the Museum. London: Ashgate. 
Prior, K. (2007) Commemorating slavery 2007: a personal view from inside the museums.

History Workshop Journal 64 (1): 200-211.

Rojas, D. (2014) Will the Caribbean Reparations Initiative inspire a revitalization of the US movement? The Nation 23 May. http://www.thenation.com/article/will-caribbean-reparationsinitiative-inspire-revitalization-us-movement/, accessed 18 August 2015.

Shelton, A. (2006) 'Museums and museum displays'. In Tilley, C. et. al. Handbook of Material Culture. London: Sage. 480-499.

Smith, L., (2010b) 'Man’s inhumanity to man' and other platitudes of avoidance and misrecognition: an analysis of visitor responses to exhibitions marking the 1807 bicentenary. Museum and Society, Nov 2010, 8 (3), 193-214

Smith, L., Cubitt, G., Wilson, R., and Fousoki, K. (Eds.) (2011) Representing Enslavement and Abolition in Museums. Ambiguous Engagement. New York: Routledge.

Smith, L. and Campbell, G. (2015) 'The elephant in the room: heritage, affect and emotion'. In: W. Logan, M. Nic Craith, U. Kockel A Companion to Heritage Studies. London: WileyBlackwell, 443-460.

Spinoza, B. ([1677]1992) Ethics, Treatise on the Emendation of the Intellect and Selected Letters. Indianapolis: Hackett. 
Thrift, N. (2008) Non-Representational Theory. Space, politics, affect. London: Routledge.

Trustram, M. (2013) The Little Madnesses of Museums in Kuhn, Annette (ed.) Little

Madnesses: Winnicott, Transitional Phenomena and Cultural Experience. London: I.B. Tauris.

$187-202$.

Waterton, E. (2010) 'Humiliated silence: multiculturalism, blame and the trope of 'moving on'. Museum and Society 8 (3): 128-157.

Widder, N. (2008) 'From Negation to Disjunction in a World of Phantasms and Simulacra:

Deleuze and Melanie Klein'， Deleuze Studies Conference, August, 2008 . (Note: A paper with the same title that was developed from this conference presentation has been published in Deleuze Studies, vol. 3, issue 2 [December, 2009], pp. 207-223.)

Wilson, R. (2010) 'Rethinking 1807: museums, knowledge and expertise'. Museum and Society $8(3), 165-179$.

Winnicott, D.W. (1991 [1971]) Playing and Reality. London: Routledge.

Witcomb, A., (2013) Understanding the role of affect in producing a critical pedagogy for history museums. Museum Management and Curatorship. 28 (3) 255-271. 
